\title{
Longitudinal surveillance of outpatient tetracycline, sulfonamide-trimethoprim and 'other' antimicrobial use in Canada, 1995 to 2010
}

\author{
Shiona K Glass-Kaastra PhD ${ }^{1}$, Rita Finley $\mathrm{MSc}^{1}$, Jim Hutchinson MD FRCPC ${ }^{2}$, David M Patrick MD FRCPC MHSc ${ }^{3,4}$, \\ Karl Weiss MD MSc FRCPC ${ }^{5}$, John Conly MD FRCPC FACP $6,7,8$
}

SK Glass-Kaastra, R Finley, J Hutchinson, DM Patrick, $\mathrm{K}$ Weiss, J Conly. Longitudinal surveillance of outpatient tetracycline, sulfonamide-trimethoprim and 'other' antimicrobial use in Canada, 1995 to 2010. Can J Infect Dis Med Microbiol 2014;25(2):113-117.

INTRODUCTION: Monitoring the volume and patterns of use of antimicrobial agents is important in light of antimicrobial resistance. OBJECTIVE: To assess the use of three antimicrobial groups - tetracycline, sulfonamide-trimethoprim and 'other' antimicrobials - within Canadian provinces over time.

METHODS: Prescription counts from 1995 to 2010 were acquired for the tetracycline and sulfonamide-trimethoprim groups of antimicrobials, and from 2001 to 2010 for the 'other' antimicrobial group. Linear mixed models were produced to assess differences among provinces and over time while accounting for repeated measurements. Prescription rate, defined daily dose per 1000 inhabitant-days and defined daily doses per prescription measures for the year 2009 were also compared with those reported by participating European Union countries to determine where Canadian provinces rank in terms of antimicrobial use among these countries.

RESULTS: Prescribing of all three groups varied according to province and over time. Tetracycline and sulfonamide-trimethoprim group prescribing were significantly reduced over the study period, by $36 \%$ and $61 \%$, respectively. Prescribing of the 'other' antimicrobial group increased in all provinces from 2001 to 2010 with the exception of Prince Edward Island, although by varying amounts (10\% to $61 \%$ increases).

DISCUSSION: The overall use of antimicrobials in Canada has dropped from 1995 to 2010, and the tetracycline and sulfonamidetrimethoprim groups have contributed to this decline. The use of the 'other' antimicrobials has increased, however. These results may suggest that switches are being made among these groups, particularly among the antimicrobials used to treat urinary tract infections.

Key Words: Antimicrobial use; Metronidazole; Prescribing patterns; Surveillance; Tetracycline

$\mathrm{T}$ he current article presents data on the use of oral tetracycline, sulfonamide-trimethoprim and 'other' antimicrobials by the outpatient population in Canada. Antimicrobials included in the 'other' category are: chloramphenicol, erythromycin with sulfisoxazole, fosfomycin, fusidic acid, kanamycin, linezolid, methenamine mandelate, metronidazole, neomycin, nitrofurantoin and vancomycin. These classes were defined by the WHO's Anatomical Therapeutic Classification system classes J01A, J01E and J01X (1). Previous research has determined that provincial variation exists in

\section{La surveillance longitudinale de l'utilisation de tétracycline, de sulfonamide-triméthoprime et d' " autres " antimicrobiens en consultations externes au Canada entre 1995 et 2010}

INTRODUCTION : Il est important de surveiller le volume et le mode d'utilisation des antimicrobiens compte tenu de la résistance antimicrobienne.

OBJECTIF : Évaluer l'utilisation de trois groupes d'antimicrobiens, soit la tétracycline, la sulfonamide-triméthoprime et d' « autres » antimicrobiens dans les provinces canadiennes au fil du temps.

MÉTHODOLOGIE : Les chercheurs ont obtenu le nombre de prescriptions des groupes de tétracycline et de sulfonamide-triméthoprime entre 1995 et 2010 et du groupe d'« autres » antimicrobiens entre 2001 et 2010. Ils ont produit des modèles linéaires mixtes pour évaluer les différences entre les provinces et dans le temps tout en tenant compte des mesures répétées. Ils ont également comparé le taux de prescriptions, les doses quotidiennes définies par 1000 habitants-jours et les doses quotidiennes définies par mesures de prescription à ceux des pays participants de l'Union européenne en 2009 pour déterminer le classement des provinces canadiennes en matière d'utilisation d'antimicrobiens au sein de ces pays.

RÉSULTATS : Les prescriptions des trois groupes de médicaments variaient selon la province et dans le temps. La prescription des groupes de tétracycline et de sulfonamide-triméthoprime a diminué considérablement pendant la période de l'étude, soit de $36 \%$ et de $61 \%$, respectivement. La prescription du groupe d'« autres » antimicrobiens a augmenté dans toutes les provinces entre 2001 et 2010, à l'exception de l'Île-du-Prince-Édouard, mais selon des taux différents (augmentations de $10 \%$ à $61 \%$ ).

EXPOSÉ : L'utilisation globale d'antimicrobiens a diminué au Canada entre 1995 et 2010, et les groupes de tétracycline et de sulfonamidetriméthoprime y ont contribué. L'utilisation d'« autres » antimicrobiens a toutefois augmenté. Ces résultats laissent peut-être supposer des substitutions entre ces groupes, notamment entre les antimicrobiens utilisés pour soigner les infections urinaires.

the dynamics of antimicrobial use $(2,3)$ as well as among classes of antimicrobials at the national level (2). However, to our knowledge, an assessment of these three classes at the provincial level has not been undertaken. These three classes may be used to treat a range of conditions: the tetracyclines are often used to manage dermatological conditions such as acne (4), while the most common use for nitrofurantoins (part of the 'other' antimicrobial group) is as a treatment option for uncomplicated urinary tract infections (UTIs) (5). Furthermore, metronidazole, also included in the 'other' antimicrobial

${ }^{1}$ Public Health Agency of Canada, Centre for Food-borne, Environmental and Zoonotic Infectious Diseases, Guelph, Ontario; ${ }^{2}$ Division of Medical Microbiology, Island Medical Program, University of British Columbia; ${ }^{3}$ British Columbia Centre for Disease Control; ${ }^{4}$ School of Population and Public Health, University of British Columbia, Vancouver, British Columbia; ${ }^{5}$ University of Montreal, Department of Infectious Diseases and Microbiology, Hôpital Maisonneuve-Rosemont, Montreal, Quebec; ${ }^{6}$ Department of Medicine; ${ }^{7}$ Department of Microbiology, Immunology and Infectious Diseases; ${ }^{8}$ Department of Pathology and Laboratory Medicine, University of Calgary, Calgary, Alberta Correspondence: Ms Rita Finley, Centre for Food-borne, Environmental and Zoonotic Infectious Diseases, Public Health Agency of Canada, 255 Woodlawn Road, Unit 120, Guelph, Ontario N1H 8J1. Telephone 519-826-2213, fax 519-826-2244, e-mail rita.finley@phac-aspc.gc.ca 
TABLE 1

Individual antimicrobials included within the tetracycline, sulfonamide-trimethoprim and 'other' classes of antimicrobials dispensed in Canada, 2000 to 2010

\begin{tabular}{ll}
\hline Class & Antimicrobials \\
\hline Tetracycline & Demeclocycline, doxycycline, minocycline, tetracycline \\
Sulfonamide-trimethoprim & Sulfadiazine, sulfadiazine with trimethoprim, sulfamethizole, sulfamethoxazole, sulfamethoxazole with trimethoprim, \\
& sulfapyridine, sulfisoxazole, trimethoprim \\
'Other' antimicrobials & $\begin{array}{c}\text { Chloramphenicol, erythromycin with sulfisoxazole, fosfomycin, fusidic acid, kanamycin, linezolid, methenamine mandelate, } \\
\text { metronidazole, neomycin, nitrofurantoin, vancomycin }\end{array}$ \\
\hline
\end{tabular}

TABLE 2

Proportions of prescriptions per 1000 inhabitant-days for individual drugs within the tetracycline, sulfonamide-trimethoprim and 'other' classes of antimicrobials in Canada in 2010 according to province

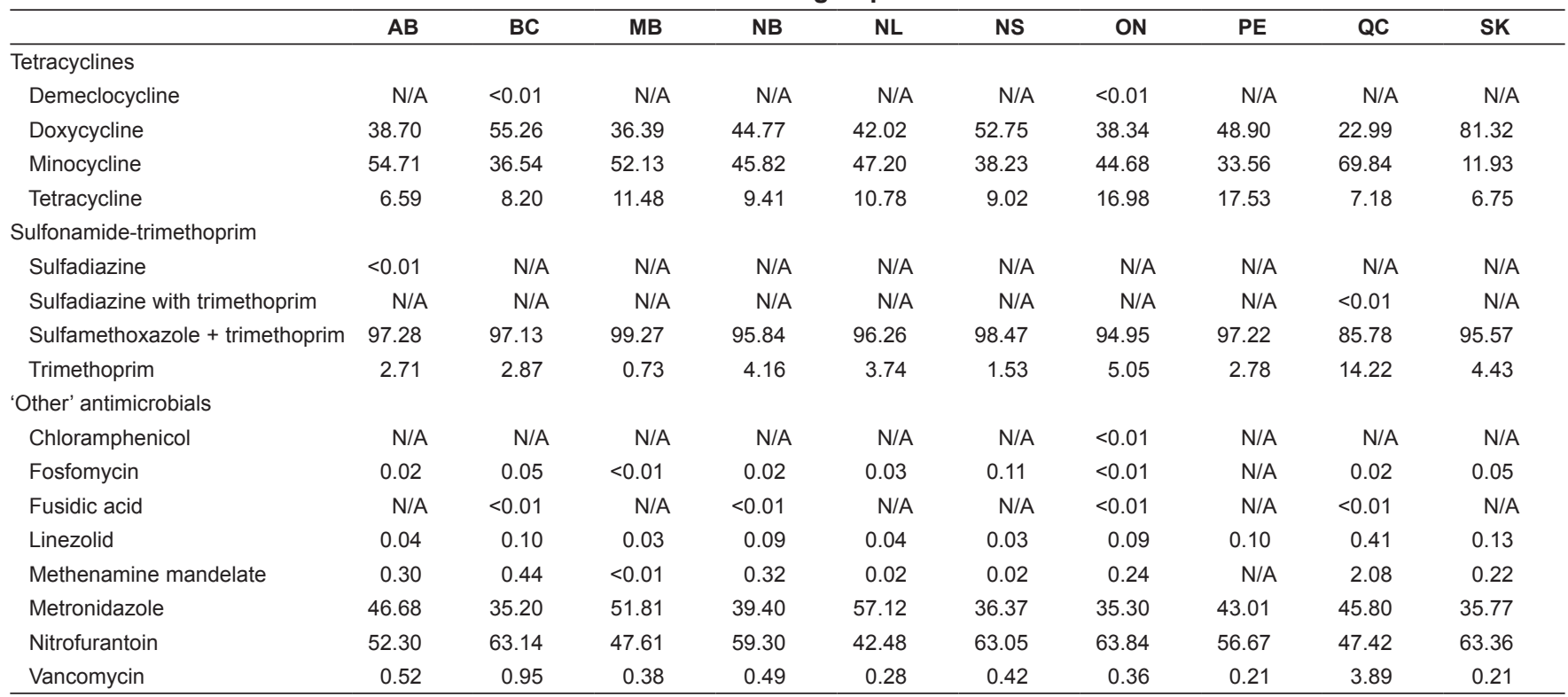

AB Alberta; BC British Columbia; MB Manitoba; N/A Drug not prescribed in the province in 2010; NB New Brunswick; NL Newfoundland and Labrador; NS Nova Scotia; ON Ontario; PE Prince Edward Island; QC Quebec; SK Saskatchewan

group, is indicated for the treatment of many anaerobic pathogens, including Clostridium difficile (6).

Data from 2009 were also used to compare the use of the three classes with measures reported in 2009 by European countries through the European Surveillance of Antimicrobial Consumption Network $(7,8)$.

\section{METHODS}

Antimicrobial prescribing and extended unit data for all individual tetracycline, sulfonamide-trimethoprim and 'other' antimicrobial drugs dispensed in Canadian provinces between 2000 and 2010 were collected by IMS Health Canada and acquired from the Public Health Agency of Canada's Canadian Integrated Program for Antimicrobial Resistance (9). In addition, supplemental prescription count data for the total tetracycline and sulfonamide classes were also collected by IMS Health Canada from 1995 to 1999 and acquired by the authors through the former Canadian Committee on Antimicrobial Resistance (10). The Canadian CompuScript dataset was developed by accessing all marketed outpatient drug data dispensed via 5700 geographically representative retail pharmacies across Canada, with provincial-level coverage ranging from $51 \%$ to $88 \%$. Geospatial extrapolation is used to infer use across all 8800 pharmacies (current to May 2013). The extrapolation method stratifies according to pharmacy size, type and province (11). This methodology nullifies any variance in store coverage over time and across geography. All data were reported monthly according to province for all new and refilled prescriptions. The Canadian CompuScript dataset included individual drug-level prescription count information, but also included manufacturer name, extended units prescribed (total number of tablets, capsules, millilitres, etc), drug strength, volume of active ingredient and patient acquisition cost. Population data were acquired from Statistics Canada (12). The prescription counts were combined with population data from Statistics Canada to develop two population-standardized measures: prescriptions per 1000 inhabitant-days (PrIDs) and the defined daily doses (DDDs) per 1000 inhabitant-days (DIDs). Data from Newfoundland and Labrador and Prince Edward Island were combined for the years from 1995 to 2004. In 2005 and subsequent years, data from these provinces were provided individually. Finally, due to an error in data acquisition methods, the full prescription count for metronidazole was not calculated for the year 2000. To reduce bias within the statistical models for this class, data from 2001 to 2010 were used.

Linear mixed models were built using a forward step-wise method to assess the provincial differences in PrIDs over time. Province and year were assessed as predictors for use at $\mathrm{P}<0.05$ and assessed for confounding effects using a $25 \%$ change cut-off in any significant coefficient. Quadratic terms for year were assessed at $\mathrm{P}<0.05$ where visually appropriate to model a curvilinear relationship between time and the outcome, as well as interaction terms between province and year, and province with the quadratic term for year. First-order autoregressive correlation structures were applied to models to account for repeated measures over time, and models met the assumptions of normality and homoscedasticity by consensus of normality tests at $\mathrm{P}<0.05$ and visual assessment of the residuals, respectively. Data for any outlying observations were assessed to assure that recording errors were not present; however, models were built using all observations to limit any potential bias. 
European Union antimicrobial use data from 2009 were acquired from the European Surveillance of Antimicrobial Consumption Network $(7,8)$, and rankings performed such that the country with lowest use was assigned a rank of 1 . Comparisons are made with three use measurements: DIDs, PrIDs and DDDs per prescription. All calculations and analyses were performed using SAS version 9.3 software (SAS Institute Inc, USA) for Windows (Microsoft Corporation, USA) and graphs were produced in Excel (Microsoft Corporation, USA).

\section{RESULTS}

Four, eight and 11 antimicrobials were used in outpatient antimicrobial therapy in Canada from 1995 to 2010 within the tetracycline, sulfonamide-trimethoprim and 'other' antimicrobial groups, respectively (Table 1). Within each class, prescribing rates were dominated by a smaller number of products, with two drugs within each class representing $>82 \%$ of prescribing (Table 2 ).

Tetracycline prescription rates (PrIDs) varied significantly according to province $(\mathrm{P}<0.01)$ and displayed a significant curvilinear relationship with time $(\mathrm{P}<0.001)$, where reductions were steady 1995 to 2004, followed by a nadir from 2004 to 2010 (Figure 1A). Alberta and Saskatchewan showed significantly higher prescribing of tetracyclines than Manitoba, New Brunswick, Ontario and Quebec $(\mathrm{P}<0.03)$. Prescribing in New Brunswick was the lowest and was significantly different from prescribing in Alberta, Nova Scotia, Prince Edward Island and Saskatchewan $(\mathrm{P}<0.03)$.

Similar to tetracycline prescribing, a significant decline in sulfonamide-trimethoprim prescribing also occurred from 1995 to 2010, with the most dramatic decline observed from 1995 to 2004, followed by a nadir from 2004 to 2010 (Figure 1B). Significant differences in prescribing also occurred at the provincial level; sulfonamide prescribing was significantly lower in Quebec than in Manitoba, New Brunswick, Newfoundland and Labrador, Nova Scotia and Prince Edward Island $(\mathrm{P}<0.02)$. In contrast, the highest sulfonamide prescribing rates were observed in Newfoundland and Labrador, where prescribing was significantly higher than in Alberta, British Columbia, Ontario and Quebec $(\mathrm{P}<0.02)$ (Figure 1B).

A significant increase in nitrofurantoin prescribing occurred from 2000 to 2010 (Figure 1C). Significant differences in prescribing also occurred at the provincial level; nitrofurantoin prescribing was significantly lower in Quebec compared with all the other Canadian provinces $(\mathrm{P}<0.0001)$. In contrast, the highest nitrofurantoin prescribing rates were observed in Saskatchewan, where prescribing was significantly higher than the rest of Canada $(\mathrm{P}<0.0001)$ (Figure $1 \mathrm{~B})$.

Prescribing for the 'other' antimicrobial group varied according to province and year over the 2001 to 2010 time frame (Figure 1D). All provinces, with the exception of Prince Edward Island, showed an increase in the prescribing rates for the 'other' antimicrobial group; however, these increases occurred at different rates and magnitudes (Figure 1C). Because province and year interacted to create different patterns of use over time, prescribing differences were assessed for 2010 alone. Many significant differences among the provincial prescribing rates occurred during 2010; therefore, $P$ values for the pairwise comparisons of provincial prescribing in 2010 are presented in Table 3.

Provincial and Canada-level DIDs, PrIDs and DDDs per prescription from 2009 were compared with reporting European Union countries (Figure 2). For the tetracyclines, Canadian provinces ranked moderately for the DID and PrID measures, with the exception of Saskatchewan, which ranked 41 of 42 for DIDs and 19 of 26 for PrIDs. For the DDD per prescription measure, Canadian provinces ranked high in comparison with reporting European countries, being ranked between 14 (Quebec) and 27 (Nova Scotia) (Figure 2). With regard to the sulfonamide-trimethoprim group, Canadian provinces ranked relatively high in comparison with reporting European Union countries (Figure 2). However, Quebec was an exception, ranking 10 of 42 for DIDs, seventh of 27 for PrIDs and 11 of 27 for DDDs per prescription. The province with the highest rankings for the sulfonamide use measures was Newfoundland and Labrador (42 of 42 for DIDs, 21 of 27 for

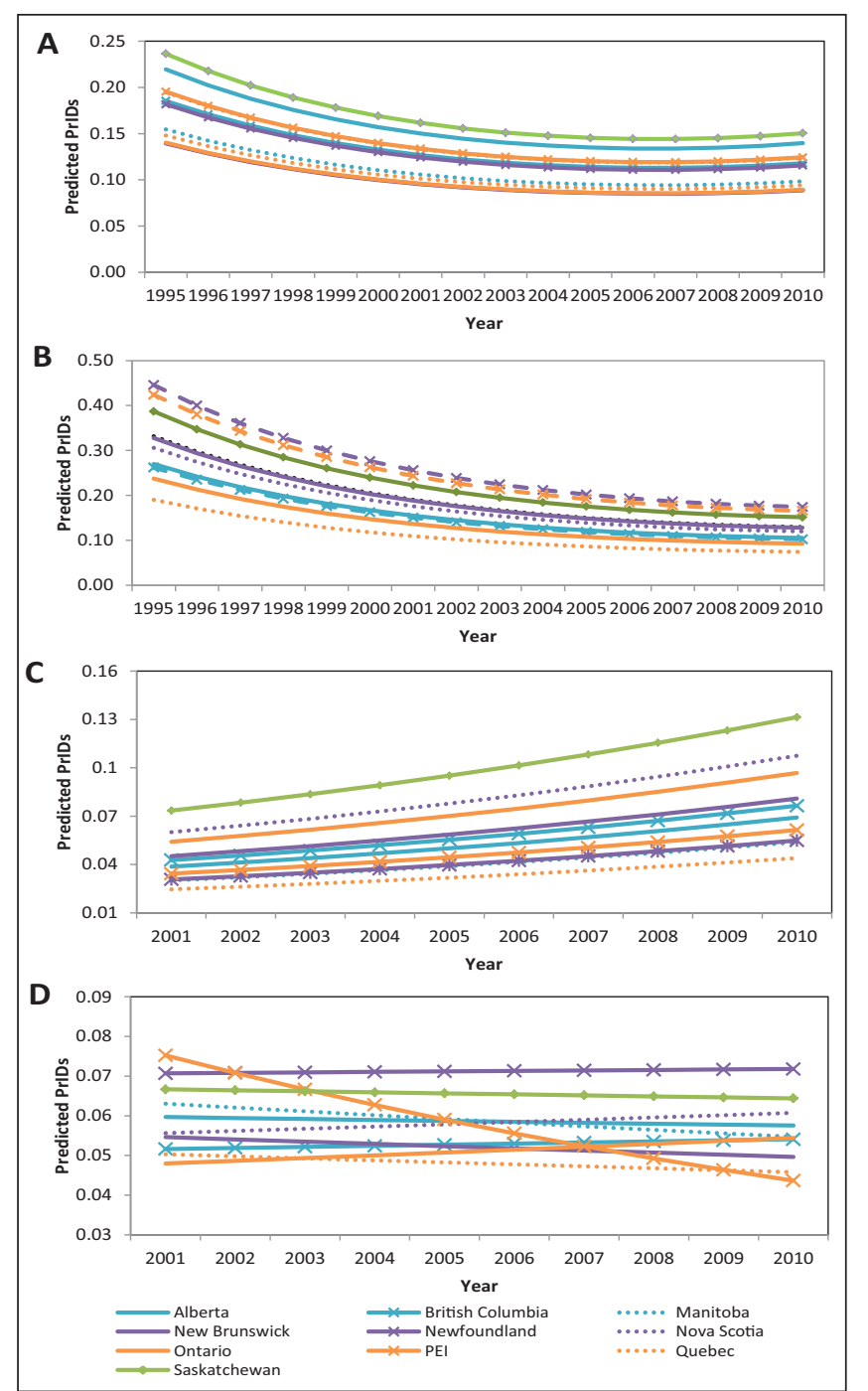

Figure 1) Linear mixed-model predictions for the models describing provincial tetracycline (A), sulfonamide-trimethoprim (B), nitrofurantoin (C) and 'other' antimicrobial (D) prescriptions per 1000 inhabitant-days (PrIDs) dispensed by outpatient pharmacies in Canada. PEI Prince Edward Island

PrIDs and 26 of 27 for DDDs per prescription). Finally, similar to the tetracyclines, Canadian provinces ranked moderately for the 'other' antimicrobial group, with Quebec ranking lower than all other provinces (13 of 42 for DIDs, eighth of 27 for PrIDs and eighth of 27 for DDDs per prescription) (Figure 2).

\section{DISCUSSION}

The use of the tetracycline, sulfonamide-trimethoprim and 'other' antimicrobial groups in Canada is driven by a small number of drugs within each group. Doxycycline and minocycline, sulfamethoxazole + trimethoprim, and metronidazole and nitrofurantoin represent the majority of prescribing of the tetracycline, sulfonamide-trimethoprim and 'other' antimicrobial groups, respectively. The remaining antimicrobials represent $<18 \%$ of prescribing within their respective classes.

Although variation in the use of individual drugs within these classes was low, the prescribing of all three groups varied significantly according to province and year. Both the tetracycline and sulfonamidetrimethoprim groups were prescribed at decreased rates from 1995 to 2010 , with an overall reduction of $36 \%$ and $61 \%$, respectively. In contrast, patterns of prescribing of the 'other' antimicrobial group differed among the provinces; however, an overall increase in prescribing occurred in all provinces with the exception of Prince Edward Island, 
TABLE 3

$P$ values for the difference in model predictions among provinces in 2010 for the linear mixed model describing 'other'* antimicrobial prescription rates from 2001 to 2010. A significant $P$ value indicates that a significant difference in prescribing exists between the provinces

\begin{tabular}{|c|c|c|c|c|c|c|c|c|c|}
\hline & $\mathrm{BC}$ & MB & NB & $\mathrm{NF}$ & NS & ON & $\mathrm{PE}$ & QC & SK \\
\hline$A B$ & $\mathrm{~ns}$ & $\mathrm{~ns}$ & 0.002 & $<0.001$ & ns & ns & $<0.001$ & $<0.001$ & 0.02 \\
\hline BC & - & ns & ns & $<0.001$ & 0.01 & ns & $<0.001$ & $<0.001$ & $<0.001$ \\
\hline MB & - & - & 0.037 & $<0.001$ & 0.025 & ns & $<0.001$ & $<0.001$ & $<0.001$ \\
\hline NF & - & - & - & - & $<0.001$ & $<0.001$ & $<0.001$ & $<0.001$ & 0.019 \\
\hline NS & - & - & - & - & - & & $<0.001$ & $<0.001$ & ns \\
\hline ON & - & - & - & - & - & - & $<0.001$ & $<0.001$ & $<0.001$ \\
\hline QC & - & - & - & - & - & - & - & - & $<0.001$ \\
\hline
\end{tabular}

*This category excludes nitrofurantoin; AB Alberta; BC British Columbia; MB Manitoba; NB New Brunswick; NF Newfoundland and Labrador; ns No significant difference in the prescriptions per 1000 inhabitant-day estimates between the provinces in 2010; NS Nova Scotia; ON Ontario; PE Prince Edward Island; QC Quebec; SK Saskatchewan

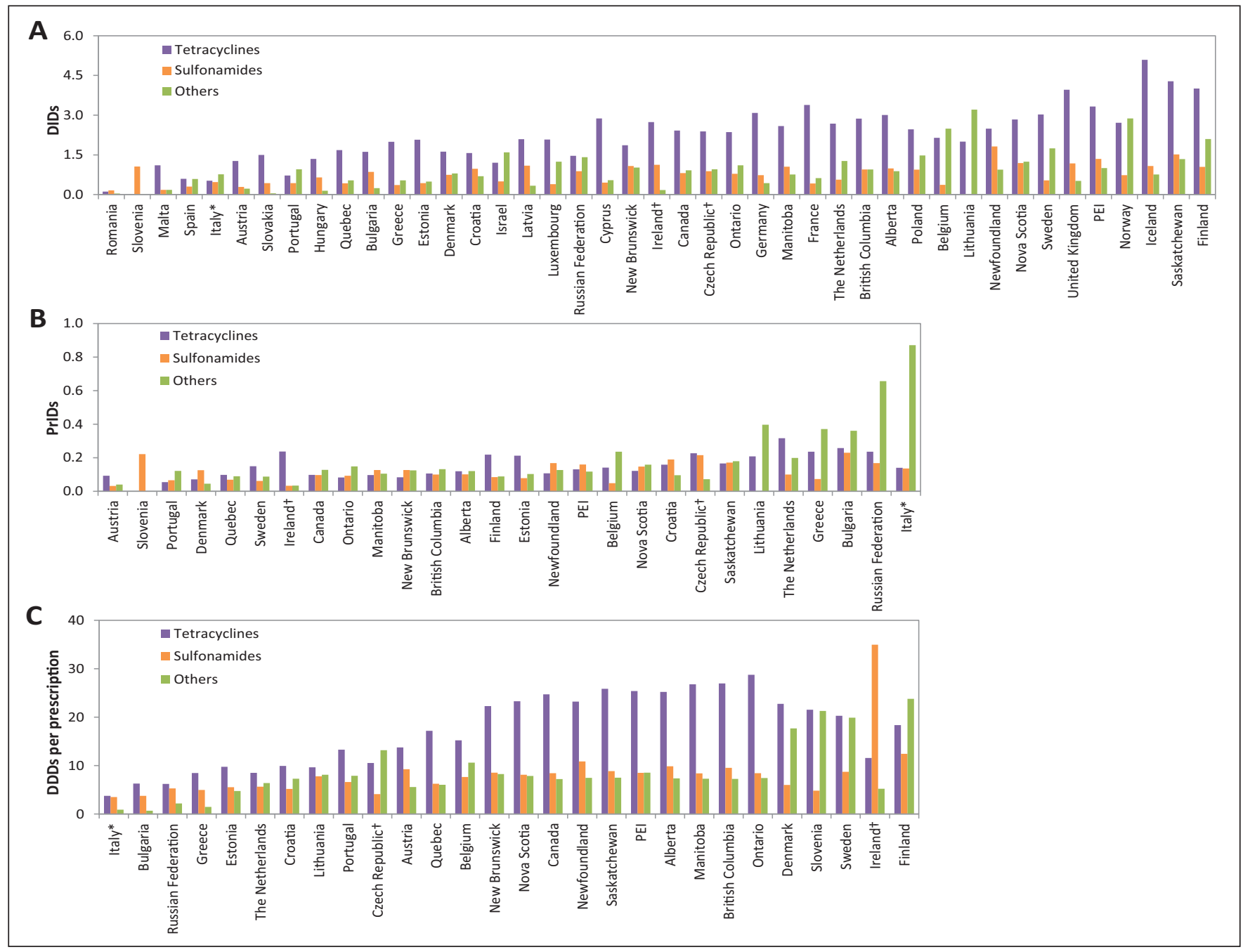

Figure 2) Comparison of total tetracycline, sulfonamide-trimethoprim, and 'other' antimicrobial use among Canada, Canadian provinces and the reporting European Surveillance of Antimicrobial Consumption Network countries according to defined daily doses (DDDs) per 1000 inhabitant-days (DIDs) (A), prescriptions per 1000 inhabitant-days (PrIDs) (B) and DDDs per prescription (C) measures in 2009. *2008 values; ${ }^{\dagger} 2007$ values. PEI Prince Edward Island

with prescribing increases that ranged from $10 \%$ to $61 \%$. These increases were due to higher levels of nitrofurantoin use across the country.

When data from 2009 were compared with reporting European Union countries $(7,8)$, Canadian provinces were relatively similar for the DID and PrID measures for the tetracyclines and all measures for the 'other' antimicrobial group. The DDD per prescription measure for the tetracyclines displayed that prescriptions in Canada included more active ingredients than those dispensed in the European Union countries. Because tetracyclines are widely used to treat acne in Canada (4), these results may reflect long-term prescribing for skin conditions rather than acute infections and, 
therefore, may display higher DDD per prescription values in Canada compared with countries where these agents are used mainly for acute infections. In contrast, use measures for the sulfonamide-trimethoprim class showed that Canada ranked higher than most reporting European Union countries. These differences may reflect geographical differences in resistance rates among communityacquired Escherichia coli strains causing UTIs (5). Continued high use rates may pose a problem for the future treatment of uncomplicated UTIs in Canada, given the increasing rates of trimethoprim and sulfamethoxazole + trimethoprim resistance in E coli in Canada and elsewhere $(13,14)$. However, reductions in the use of these products over time suggests that switches in treatment choices for uncomplicated UTIs and upper respiratory infections are occurring, especially in light of the increase observed in all provinces for the use of nitrofurantoin. An exception to the average and high rankings for tetracycline and sulfonamide use was the province of Quebec, where use of these groups was relatively low. These results are similar to those reported for overall antimicrobial, $\beta$-lactam and macrolide use in Canada (2).

\section{REFERENCES}

1. World Health Organization. ATC/DDD Index 2012. <www.whocc. no/atc_ddd_index> (Accessed January 6, 2012).

2. Government of Canada. Canadian Integrated Program for Antimicrobial Resistance Surveillance (CIPARS) Human Antimicrobial Use Short Report, 2000-2009. Guelph: Public Health Agency of Canada, 2011.

3. Glass-Kaastra SK, Finley R, Hutchinson J, et al. Variation in antimicrobial use patterns among Canadian provinces (1995-2010). 2012. 4th World HAI Forum, Les Pensières, Annecy, France, June 23 to $25,2013$.

4. Kraft J, Freiman A. Management of acne. CMAJ 2011;183:E430-E435.

5. Gupta K, Hooton TM, Naber KG, et al. International Clinical Practice Guidelines for the treatment of acute uncomplicated cystitis and pyelonephritis in women: A 2010 update by the Infectious Diseases Society of America and the European Society for Microbiology and Infectious Diseases. Clin Infect Dis 2011;52:e103-20.

6. Freeman CD, Klutman NE, Lamp KC. Metronidazole. A therapeutic review and update. Drugs 1997;54:679-708.

7. Adriaenssens N, Coenen S, Versporten A, et al. European surveillance of antimicrobial consumption (ESAC): Outpatient antibiotic use in Europe (1997-2009). J Antimicrob Chemother 2011;66(Suppl 6):vi3-vi12.

8. Adriaenssens N, Coenen S, Versporten A, et al. European surveillance of antimicrobial consumption (ESAC): Outpatient use of tetracyclines, sulphonamides and trimethoprim and other antibacterials in Europe (1997-2009). J Antimicrob Chemother 2011;66(Suppl 6):vi57-vi70.
We acknowledge the limitations to our study, which include the lack of prescription count data for individual products 1995 to 1999 , and the data collection error for the 'other' antimicrobial group in 2000. Furthermore, we acknowledge the potential for nonrepresentativeness of measured pharmacies. However, despite missing prescription counts at the individual drug level from 1995 to 1999, and despite the requirement to drop 2000 data from the 'other' antimicrobial group model, the data acquired contained sufficient information to support the linear mixed models described and to detail trends in provincial use over time. Furthermore, the large proportion of pharmacies represented in the dataset $(>67 \%$ of all Canadian pharmacies in September 2011) and the extensive extrapolation method used by IMS Health Canada supports our belief that these data truly reflect antimicrobial use patterns in Canada $(2,11)$.

DISCLAIMER: This article was prepared using data from IMS Health Canada Inc. The analyses, conclusions, opinions and statements expressed are those of the authors and not those of IMS Health Canada Inc.

9. Government of Canada. Canadian Integrated Program for Antimicrobial Resistance Surveillance (CIPARS) 2008. Guelph: Public Health Agency of Canada, 2011. <www.phac-aspc.gc.cal cipars-picra/2008/index-eng.php> (Accessed June 11, 2012).

10. National Collaborating Centre for Infectious Diseases. CommunityAcquired Antimicrobial Resistance Consultation Notes. 2010. <www.nccid.ca/files/caAMR_ConsultationNotes_final.pdf> (Accessed April 24, 2012).

11. IMS Health Canada. Unlocking the value of health information: How Canada's healthcare community uses IMS evidence-based intelligence to improve healthcare. 2007. <www.imshealth.com/ims/ Global/Content/Solutions/Solutions\%20by\%20Sector/Providers/ ValueofHealthInformation.pdf> (Accessed April 24, 2012).

12. Statistics Canada. Table 051-0001 - Estimates of population, by age group and sex for July 1, Canada, provinces and territories, annual (persons), 1971 to 2010 (table), CANSIM (database), Using E-STAT (distributor). <www5.statcan.gc.ca/cansim/ a05?lang=eng\&id $=0510001>($ Accessed March 21, 2012).

13. Walkty A, Lagacé-Wiens PR, Karlowsky JA, et al. Change in antimicrobial susceptibility of Escherichia coli urinary tract isolates at a single institution over a period of 10 years. Can J Microbiol 2012;58:345-9.

14. Kahlmeter G, Poulsen H. Antimicrobial susceptibility of Escherichia coli from community-acquired urinary tract infections in Europe: The ECO•SENS study revisited. Int J Antimicrob Agents 2012;39:45-51. 


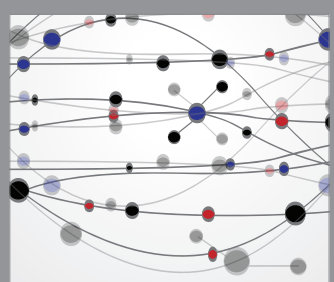

The Scientific World Journal
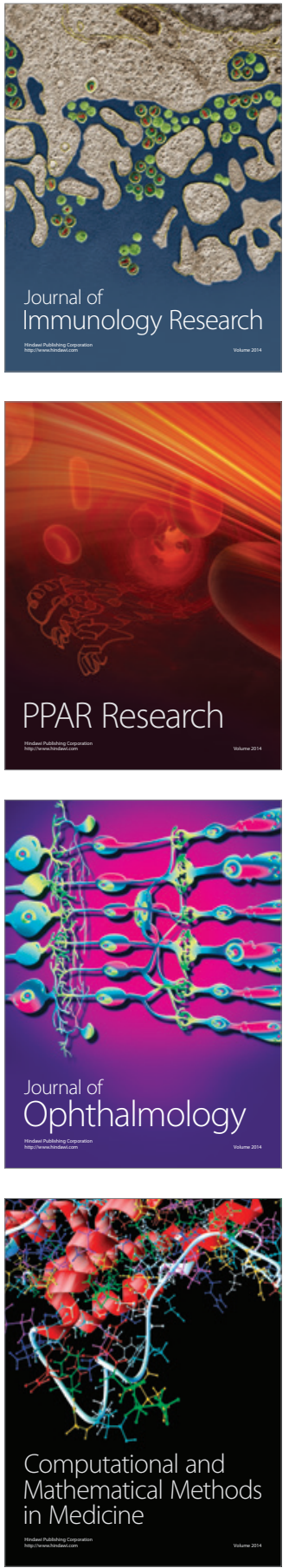

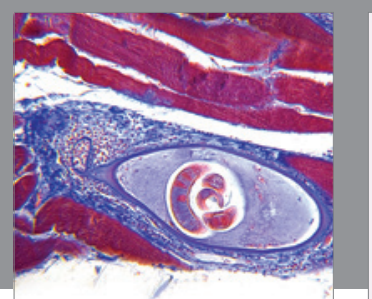

Gastroenterology Research and Practice

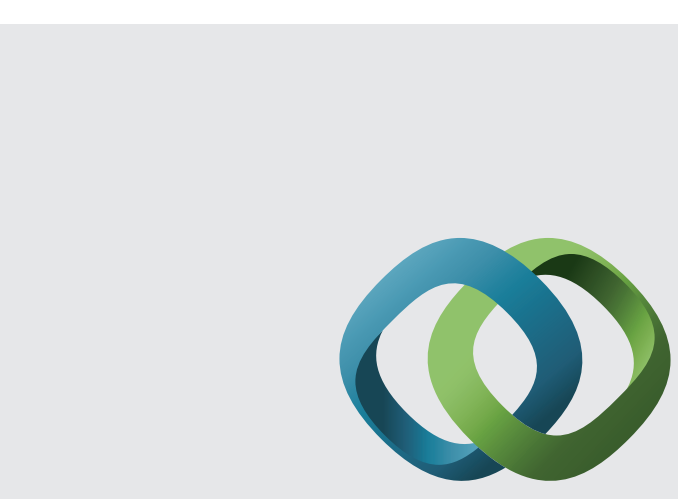

\section{Hindawi}

Submit your manuscripts at

http://www.hindawi.com
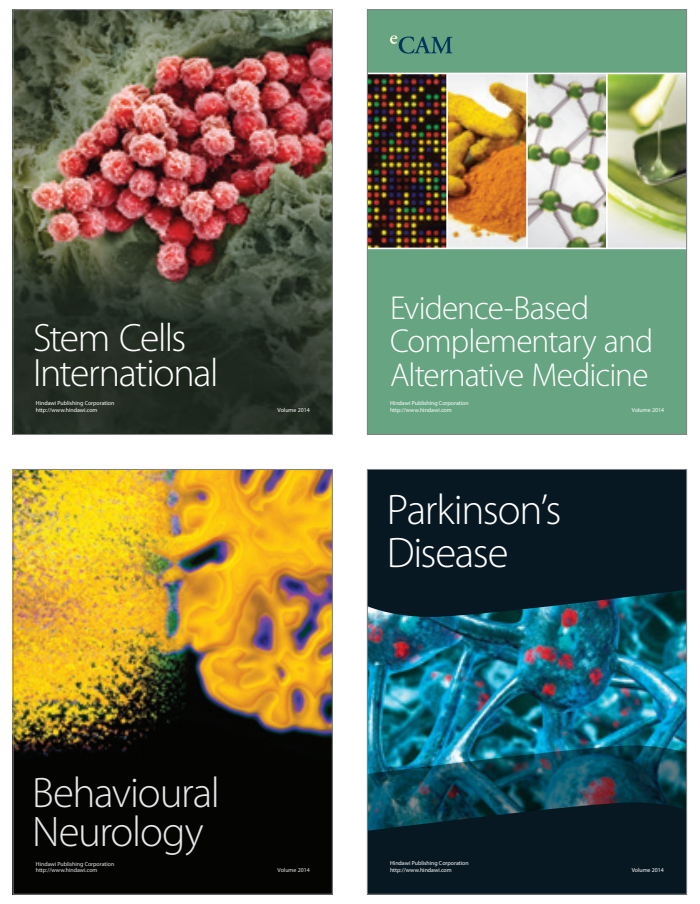
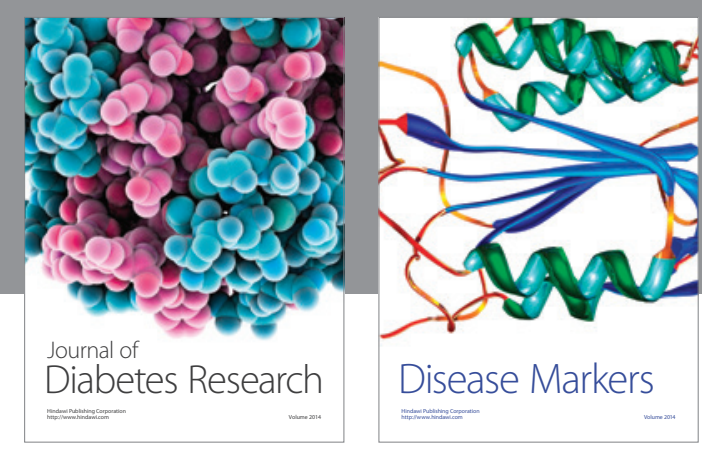

Disease Markers
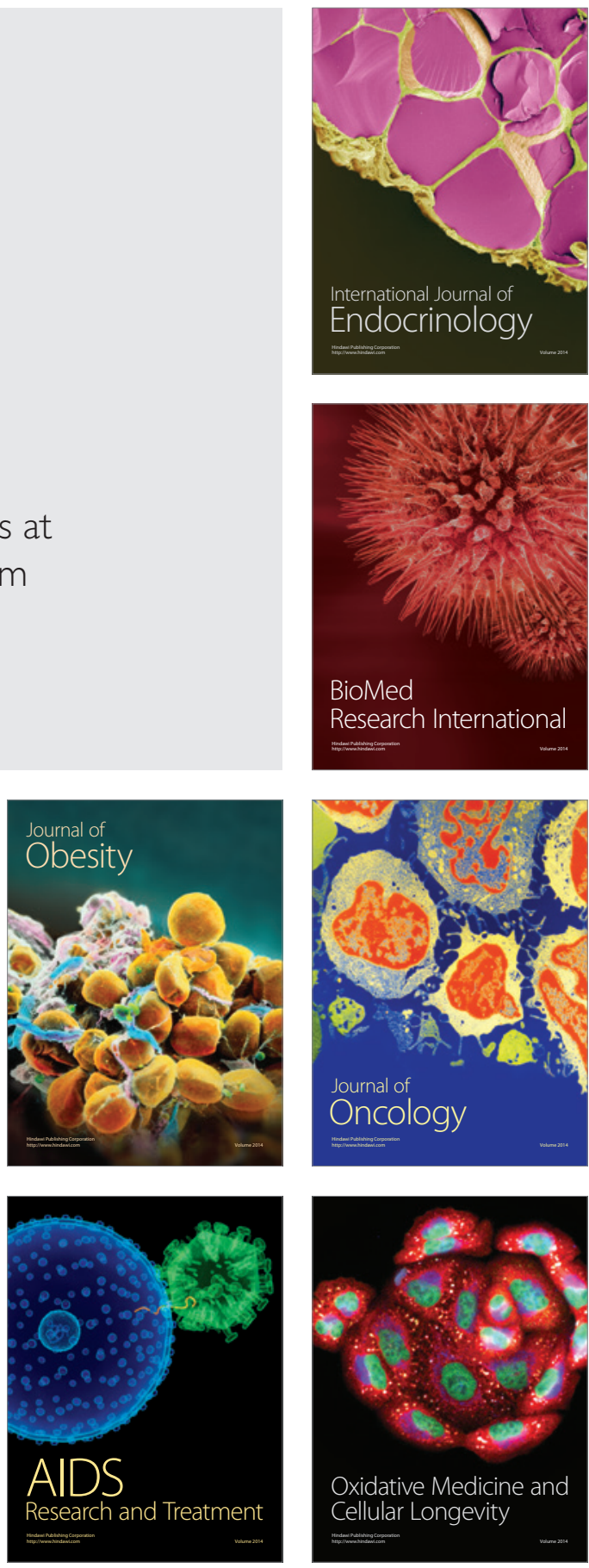